\title{
Endogenous glucocorticoids cause thymus atrophy but are protective during acute Trypanosoma cruzi infection
}

\author{
Eduardo Roggero, Ana R Pérez, Maximiliano Tamae-Kakazu, Isabel Piazzon ${ }^{1}$, Irene Nepomnaschy ${ }^{1}$, \\ Hugo O Besedovsky ${ }^{2}$, Oscar A Bottasso and Adriana del Rey ${ }^{2}$ \\ Instituto de Inmunología, Facultad de Ciencias Médicas, Santa Fé 3100, Universidad Nacional de Rosario, 2000 Rosario, Argentina \\ ${ }^{1}$ Ilex-Conicet, Instituto de Investigaciones Hematológicas, Pacheco de Melo 308, Academia Nacional de Medicina, 1425 Buenos Aires, Argentina \\ ${ }^{2}$ Department of Immunophysiology, Institute of Physiology, Medical Faculty, Deutschhausstrasse 2, Philipps University, 35037 Marburg, Germany \\ (Requests for offprints should be addressed to A del Rey; Email: delrey@mailer.uni-marburg.de)
}

\begin{abstract}
The cytokine-mediated stimulation of the hypothalamuspituitary-adrenal (HPA) axis is relevant for survival during bacterial endotoxemia and certain viral infections. However, only limited information is available regarding the effects of endogenous glucocorticoids on parasite diseases. We have studied this issue using, as a model, $\mathrm{C} 57 \mathrm{Bl} / 6$ and $\mathrm{Balb} / \mathrm{c}$ mice infected with Trypanosoma cruzi, the causal agent of Chagas' disease. These two mouse strains differ in the susceptibility to infection with the parasite. An intense stimulation of the HPA-axis was observed 3 weeks after infection in both strains, but glucocorticoid levels were already increased two- to threefold in the less susceptible Balb/c strain during the first week. Blockade of glucocorticoid receptors with
\end{abstract}

the glucocorticoid antagonist RU486, starting on day 10 after infection, partially reversed the thymic atrophy and decreased the number of $\mathrm{CD} 4{ }^{+} \mathrm{CD} 8{ }^{+}$thymocytes without affecting parasitemia and the number of inflammatory foci in the heart. However, tumor necrosis factor- $\alpha$ blood levels were increased in infected mice of both strains treated with RU486. Furthermore, the blockade of glucocorticoid receptors accelerated death in $\mathrm{C} 57 \mathrm{Bl} / 6 \mathrm{~J}$ mice and increased lethality to $100 \%$ in $\mathrm{Balb} / \mathrm{c}$ mice. The results obtained represent the first evidence that an endocrine host response that is coupled to the immune process can strongly affect the course of a parasite infection.

Journal of Endocrinology (2006) 190, 495-503

\section{Introduction}

Chagas' disease (also called American trypanosomiasis) is a major health problem in Latin American countries with approximately 18 million people in Central and South America infected with the intracellular parasite Trypanosoma cruzi and more than 100 million at risk of infection. The parasite is transmitted to humans and other mammals mostly by hematophagous insects. The human disease occurs in two stages: the acute stage shortly after the infection and the chronic stage that may develop over 10 years. Chronic infections result in various neurological disorders, damage to the heart muscle (cardiomyopathy, the most serious manifestation), and sometimes dilation of the digestive tract (megacolon and megaesophagus). When left untreated, Chagas' disease can be fatal, in most cases due to the cardiac sequelae.

Due to their different sensitivities, infected Balb/c and C57Bl/6 mice are useful models to study differences in the immune response to intracellular pathogens (Wrightsman et al. 1982, Andrade et al. 1985, Appelberg et al. 1994, Heinzel et al. 1998). We have previously shown that inoculation of T. cruzi into C57Bl/6 mice leads to a progressive and lethal disease with profound thymic atrophy and loss of
$\mathrm{CD} 4{ }^{+} \mathrm{CD} 8{ }^{+}$thymocytes, while more than $50 \%$ of the Balb/c mice recover (Roggero et al. 2002). Increased morbidity of C57Bl/6 mice does not seem to result from an aggravated infection since parasitemia, myocardial parasite nests and amastigote counts in peritoneal macrophages were comparable in both strains. The main differences between infected $\mathrm{C} 57 \mathrm{Bl} / 6 \mathrm{~J}$ and $\mathrm{Balb} / \mathrm{c}$ mice were observed in cytokine levels. Although blood levels of tumor necrosis factor- $\alpha$ (TNF- $\alpha$ ), interferon- $\gamma$ (IFN- $\gamma$ ), interleukin (IL)-1 $\beta$ (IL-1 $\beta$ ), and IL-10 increased in both strains of mice, $\mathrm{C} 57 \mathrm{Bl} / 6$ mice display higher TNF- $\alpha$, lower IL-10, and IL-1 $\beta$ levels than $\mathrm{Balb} / \mathrm{c}$ mice. Interestingly, peritoneal macrophages from $\mathrm{C} 57 \mathrm{Bl} / 6 \mathrm{~J}$ mice also produce more TNF- $\alpha$ than those from $\mathrm{Balb} / \mathrm{c}$ mice when exposed to the parasite in vitro. These results suggest that the fatal outcome in C57Bl/ 6 mice may be linked to an unbalanced relation between cytokines, a proposal that agrees with the report that the cachexia associated with $T$. cruzi infection in mice is attenuated by antibodies to TNF- $\alpha$ (Truyens et al. 1995).

In the past two decades, there have been several studies on the immunopathogenesis of $T$. cruzi infection, but there are few reports available on the role that neuroendocrine mechanisms may play in the development of the disease 
(Savino et al. 1989, Leite de Moraes et al. 1991). We have chosen to study, in particular, the significance of endogenous glucocorticoids levels for the course of T. cruzi infection, because the cytokine pattern and the thymic alterations described supported the hypothesis that the hypothalamuspituitary-adrenal (HPA) axis might be activated in the model of Chagas' disease used in our studies. TNF- $\alpha$, IL-1 $\beta$, IL- 6 , and IFN $-\gamma$, which can stimulate the HPA axis (for review, see Besedovsky \& del Rey, 1996, Turnbull \& Rivier, 1999), are among the cytokines released during T. cruzi infection (Gao \& Pereira, 2002, Roggero et al. 2002). Although cytokines produced during infectious diseases can be initially protective, they can also cause tissue injury and metabolic derangements when produced in excess. These deleterious effects can be expressed when endogenous levels of glucocorticoids are not enough to control the production of pro-inflammatory cytokines (Sapolsky et al. 2000). In particular, an insufficient control of TNF- $\alpha$ production is expected to mediate harmful effects since, as mentioned above, it has been shown that this cytokine is the main mediator of the lethal course of experimental T. cruzi infection (Truyens et al. 1995). Thus, to gain some insight into the possible activation of the HPA axis accompanying this protozoan infection, plasma corticosterone levels were measured at different times during the acute infection in Balb/c and C57Bl mice. The effect of endogenous glucocorticoids on the susceptibility and clinical course of the disease was evaluated by blockade of glucocorticoid receptors. Furthermore, since this hormone affects thymic cell turnover and negative selection (Jondal et al. 1993), the number of $\mathrm{CD} 4{ }^{+} \mathrm{CD} 8{ }^{+}$thymocytes was determined in infected C57Bl/ $6 \mathrm{~J}, \mathrm{Balb} / \mathrm{c}$ mice, and in mice of both strains treated with the glucocorticoid receptor antagonist RU486. TNF- $\alpha$ levels in plasma were also evaluated in these animals. The results obtained show that the HPA axis is stimulated during T. cruzi infection, although earlier in the less susceptible Balb/c strain, and that the blockade of this endocrine response prevents thymus involution, but aggravates the disease.

\section{Materials and Methods}

Parasite, mice, and infection

The Tulahuén strain of $T$. cruzi used in this study was maintained by serial passages in Balb/c suckling mice. Male $\mathrm{Balb} / \mathrm{c}$ and $\mathrm{C} 57 \mathrm{Bl} / 6$ mice were bred in the animal facilities of the Medical Faculty of Rosario. Experimental procedures were approved by the local ethical committee. One hundred trypomastigotes suspended in $100 \mu \mathrm{l}$ physiological saline were injected s.c. (50 $\mu \mathrm{l}$ in each flank), when mice were 8-10 weeks old. Bloodstream forms of T. cruzi were counted under standardized conditions by direct microscopic observation of $5 \mu \mathrm{l}$ heparinized blood obtained from the tip of the tail. Data are expressed as number of parasites/50 fields.

\section{Corticosterone determinations}

Mice were housed individually for 1 week before the experiments were started and kept single-caged throughout the experiments in temperature-, humidity-, and light (12 h light: $12 \mathrm{~h}$ darkness cycles)-controlled rooms. Plasma samples for hormone determinations were obtained from the tip of the tail under light ether narcosis between 0800 and $1000 \mathrm{~h}$ at 3, 5, 7, 14, and 18 days postinjection (p.i.). Blood samples were also obtained from age- and sex-matched controls subjected to the same experimental conditions. Plasma corticosterone levels were determined by RIA as previously described (Besedovsky et al. 1991).

\section{Blockade of glucocorticoid receptors}

Mifepristone (RU486; Sigma) dissolved in sesame oil (Sigma) was inoculated i.p. at a daily dose of $1 \mathrm{mg}$ in $0.1 \mathrm{ml}$ vehicle, starting 2 or 10 days after infection and until the end of the experiments. Control mice received $0.1 \mathrm{ml}$ sesame oil under the same schedule.

\section{Adrenalectomy}

Mice were anesthetized with $100 \mathrm{mg} / \mathrm{kg}$ ketamine and $2 \mathrm{mg} / \mathrm{kg}$ xylazine and bilateral adrenalectomy was performed via a dorsal approach. Two small incisions were made on each side of the back just below the rib cage and the adrenal glands were removed with curved forceps. Sham mice were operated in a similar manner, but without removing the adrenals. The animals were used 1 week after the operation for further experimentation.

\section{Heart histology}

Hearts were removed on day 18 p.i., sliced transversally in three sections, and fixed in buffered formalin. Paraffinembedded $5 \mu \mathrm{m}$ sections were stained with hematoxylin and eosin. Tissue parasitism was evaluated by counting the number of parasite nests that were visualized in three sections. The three sections were examined by an experienced pathologist blinded to the study groups.

\section{Thymus weight}

Thymi were removed at 18 days p.i. and weighed. The relative thymus weight was calculated as thymus weight/body weight $\times 100$.

\section{Flow cytometry analysis}

Thymocytes $\left(10^{6}\right)$ resuspended in buffer (RPMI-1640 without phenol red supplemented with $3 \%$ fetal bovine serum, $0 \cdot 1 \%$ sodium azide, and $10 \mathrm{mM} \mathrm{N}$-2-hydroxyethylpiperazine- $\mathrm{N}^{\prime}-2$-ethane sulfonic acid sodium salt (HEPES)) were stained with cychrome-coupled anti-CD4 and 
phycoerythrin-coupled anti-CD8a monoclonal antibodies (PharMingen, San Diego, CA, USA). A minimum of $10^{5}$ events was acquired using a FACScan flow cytometer (Becton Dickinson, New Jersey, USA). Living cells were gated on the basis of forward- and side-cell scatter. Results were analyzed using Cell Quest software (Becton Dickinson).

\section{Determination of TNF- $\alpha$ levels in plasma}

Mice were bled by cardiac puncture at 18 days p.i. Blood was collected in sterile, endotoxin-free tubes and kept refrigerated until centrifugation. The serum was stored frozen at $-20^{\circ} \mathrm{C}$ until used. TNF- $\alpha$ and IL- 6 concentrations were evaluated by ELISA, using commercially available kits (R\&D; detection limits $5 \cdot 1 \mathrm{pg} / \mathrm{ml}$ for TNF- $\alpha$ and $15.6 \mathrm{pg} / \mathrm{ml}$ for IL-6). All the samples were assayed in duplicate.

\section{Statistical analysis}

Results are expressed as means \pm s.E.M. Data were analyzed using one-way ANOVA followed by Fisher's test for multiple comparisons or by nonparametric tests (Mann-Whitney $U$-test for two samples and Kruskall-Wallis test for $k$ samples).

\section{Results}

Changes in endogenous glucocorticoid levels during acute T. cruzi infection

We first analyzed blood glucocorticoid levels during the course of acute infection in C57Bl/6 and Balb/c mice. Basal corticosterone levels in blood of control C57Bl/6 mice $(0.37 \pm 0.03 \mu \mathrm{g} / \mathrm{dl}, \quad n=25)$ were significantly lower $(P<0 \cdot 0002)$ than those of the Balb/c counterparts $(0 \cdot 76 \pm$ $0 \cdot 11 \mu \mathrm{g} / \mathrm{dl}, n=18)$. No major changes were detected in glucocorticoid blood levels in C57Bl/6J mice during the first week following inoculation with $100 \mathrm{~T}$. cruzi trypomastigotes, whereas Balb/c mice showed a progressive increase in the levels of this hormone on days 3,5 , and 7 following injection of the parasite (Fig. 1). Two weeks after infection, increased levels of corticosterone were detected in both mouse strains. The analysis of the increase in glucocorticoid blood levels relative to the mean levels of control mice also showed that, during the early phase of infection, the HPA-axis of Balb/c mice was, in contrast to C57Bl/6 mice, already stimulated. For example, on day 5 after T. cruzi injection, there was no significant increase in corticosterone blood levels in C57Bl/6 $\mathrm{J}$ mice relative to the untreated controls, whereas the levels were about twofold increased in infected $\mathrm{Balb} / \mathrm{c}$ mice. However, 18 days after injection, the relative increase in glucocorticoid levels was twofold higher in C57Bl/6 compared to Balb/c mice.
Effect of blocking glucocorticoid receptors on corticosterone levels and $\mathrm{CD}^{+}{ }^{+} \mathrm{CD} 8^{+}$thymic cells

The finding described above prompted us to analyze whether the blockade of glucocorticoid receptors affects corticosterone levels and the changes in the thymus observed during T. cruzi infection. For this purpose, Balb/c and C57Bl/6 mice infected with 100 T. cruzi trypomastigotes received the steroid receptor antagonist RU486 once daily from day 10 p.i. till the end of the experiment. The control mice received the vehicle alone at the same intervals. As can be seen in Table 1, the blockade of glucocorticoids receptors in infected mice resulted in a more pronounced elevation of corticosterone levels on day 18 p.i. when compared to infected mice injected with the vehicle. Plasma corticosterone concentrations in the control mice receiving RU486 did not differ from vehicle-only injected controls.

In $\mathrm{C} 57 \mathrm{Bl} / 6$ mice, a clear reduction (about $70 \%$ ) in the weight of the thymus was observed 18 days after infection, while a less marked decrease (about 36\%) in the weight of this

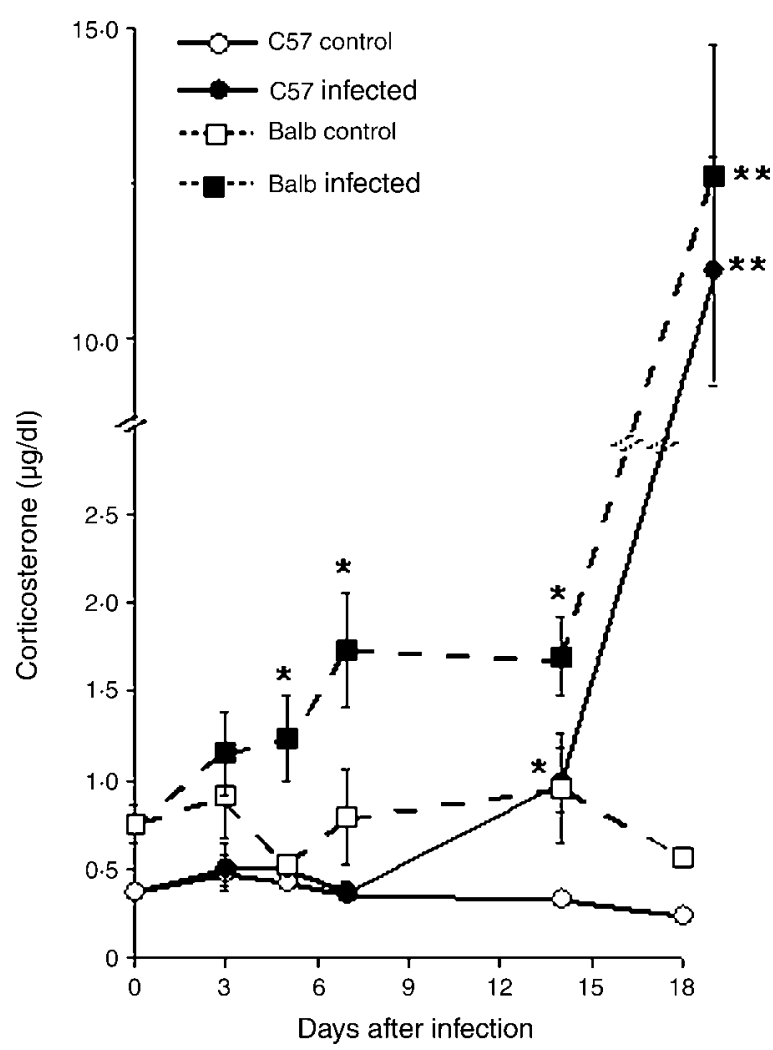

Figure 1 Changes in endogenous glucocorticoid levels during acute $T$. cruzi infection. C57Bl/6 and Balb/c mice received $100 \mathrm{~T}$. cruzi trypomastigotes suspended in $100 \mu$ l physiological saline. Controls received the same volume of the vehicle alone. Blood samples were obtained from the tip of the tail at the times indicated in the figure. Results (a representative experiment from two independent series) are expressed as means \pm s.E.M. of determinations performed in $4-6$ mice/group. ${ }^{*} P<0.05$ and ${ }^{* *} P<0.01$ vs control of the corresponding strain (ANOVA followed by Fisher's test for multiple comparisons). 
Table 1 Corticosterone levels in C57Bl/6J and Balb/c mice infected with T. cruzi and treated with RU486

C57BI/6]

\begin{tabular}{|c|c|c|c|c|c|}
\hline$n(\mu \mathrm{g} / \mathrm{dl})$ & Corticosterone & Relative increase & $n(\mu \mathrm{g} / \mathrm{dl})$ & Corticosterone & Relative increase \\
\hline 5 & $0.24+0.02$ & 1 & 5 & $0.95+0.16$ & 1 \\
\hline 5 & $0 \cdot 30 \pm 0.02$ & $1 \cdot 25$ & 4 & $1 \cdot 00 \pm 0 \cdot 27$ & $1 \cdot 05$ \\
\hline 4 & $11 \cdot 00 \pm 1 \cdot 70^{*}$ & $45 \cdot 8$ & 5 & $13 \cdot 80 \pm 1 \cdot 75^{*}$ & $14 \cdot 6$ \\
\hline 5 & $19 \cdot 90 \pm 4 \cdot 90+$ & $83 \cdot 3$ & 5 & $19 \cdot 05 \pm 3 \cdot 82+$ & $20 \cdot 05$ \\
\hline
\end{tabular}

Control mice and mice infected with T. cruzi received RU486 from day 10 after infection or the corresponding vehicle as described in Material and Methods. Corticosterone levels in plasma were determined 17 days after infection. Results are expressed as means \pm s.E.M. A representative experiment from two independent series is shown. ${ }^{*} P<0 \cdot 01$ vs control + vehicle; tvs control + RU of the corresponding strain (Kruskall-Wallis test).

organ was observed in Balb/c mice (Table 2). Injection of RU486 alone induced a comparable decrease in the weight of this organ in both strains (21-24\%). However, when the antagonist was administered to infected animals, the weight of the thymus was significantly recovered in both $\mathrm{C} 57 \mathrm{Bl} / 6$ and $\mathrm{Balb} / \mathrm{c}$ mice. Comparable results were obtained when the weight of the organ was calculated relative to the body weight.

Flow cytometric studies were performed to study whether $\mathrm{CD}^{+}{ }^{+} \mathrm{CD}^{+}{ }^{+}$(double positive, DP) thymic cells were affected by the increased levels of glucocorticoids detected during infection with T. cruzi and by treatment with the antagonist. Cell suspensions from thymi obtained 18 days after infection were used for this analysis. Infection with T. cruzi induced a decrease in the percentage of DP thymocytes in the mice of both strains, but the decrease was significantly more pronounced in $\mathrm{C} 57 \mathrm{Bl} / 6$ than in the Balb/c mice (Table 3). However, the blockade of glucocorticoid receptors by RU486 administration resulted in a significant recovery of the relative proportion of DP thymic cells in infected mice of both strains.

\section{Blockade of glucocorticoid receptors does not affect parasitemia and myocardial lesions}

The blockade of glucocorticoid receptors by daily administration of RU486, starting 10 days after infection with T. cruzi, did not significantly affect parasitemia and the number of inflammatory foci in the heart and only a tendency towards a decrease in the number of amastigote nests was observed in both strains of mice (Table 4).

\section{Endogenous glucocorticoids prolong survival of T. cruzi-infected mice}

As mentioned, infection of $\mathrm{C} 57 \mathrm{Bl} / 6$ mice with $T$. cruzi is lethal. Under our conditions, $\mathrm{C} 57 \mathrm{Bl} / 6$ mice that received only 100 parasites had a mean survival time of $21 \cdot 8 \pm$ $0 \cdot 5$ days. Daily treatment with the blocker RU486, starting on day 10 after inoculation, decreased the mean survival time to $16 \cdot 8 \pm 0 \cdot 3$ days. The cumulative percentage of survival time is shown in Fig. 2. The Balb/c strain is more resistant to infection, since more than half of the animals that received the same number of parasites as the $\mathrm{C} 57 \mathrm{Bl} / 6$ mice survive (Roggero et al. 2002). In the present study, only $40 \%$ of the infected $\mathrm{Balb} / \mathrm{c}$ mice died within $23 \cdot 7 \pm 0 \cdot 4$ days of infection. Treatment with the blocker RU486 not only significantly shortened the survival time, but also resulted in death of all the infected Balb/c mice (Fig. 2).

In another series of experiments, both mouse strains were treated with RU486 from day 2 (RU2) after T. cruzi inoculation and the survival time was compared with blockade starting on day 10 (RU10) p.i. (Table 5). In C57Bl/6 mice, there was no difference between the RU2 and RU10 groups. In contrast, $\mathrm{Balb} / \mathrm{c}$ mice treated with the blocker from day 2 died earlier than those in which the blockade was delayed until day 10 p.i.

Table 2 Thymus weight of T. cruzi-infected mice treated with RU486

\section{C57Bl/6]}

Thymus weight (mg)

\section{Treatment}

Control + vehicle

Control+RU

Infected + vehicle

Infected + RU

$42 \cdot 4 \pm 4 \cdot .6$
$33 \cdot 6 \pm 2 \cdot 2^{*}$
$12 \cdot 8 \pm 2 \cdot 0$
$19 \cdot 8 \pm 2 \cdot 5+$

Balb/c

\begin{tabular}{|c|c|}
\hline Thymus (mg) & Relative weight \\
\hline $34 \cdot 0 \pm 4 \cdot 0$ & $8 \cdot 3 \pm 1 \cdot 1$ \\
\hline $25 \cdot 7 \pm 2 \cdot 5$ & $7 \cdot 3 \pm 0 \cdot 8$ \\
\hline $21 \cdot 7 \pm 1 \cdot 4$ & $7 \cdot 4 \pm 0.7$ \\
\hline $27 \cdot 1 \pm 1 \cdot 9+$ & $9 \cdot 6 \pm 0.7$ \\
\hline
\end{tabular}

Mice infected with T. cruzi received RU486 from day 10 after infection until day 17, when they were killed and the weight of the thymus was determined. Controls received the vehicle alone. Results are expressed as means \pm s.E.M. from 4 to 7 mice/group. The relative weight was calculated as: thymus weight/mouse weight $\times 100$. A representative experiment from two independent series is shown. ${ }^{*} P<0.05$ vs control+vehicle of the corresponding strain; $+P<0.01$ vs infected+vehicle of the corresponding strain (Kruskall-Wallis test). 
Table $3 \mathrm{CD}^{+}{ }^{+} \mathrm{CD} 8{ }^{+}$thymocytes in $T$. cruzi-infected mice treated with RU486

\begin{tabular}{|c|c|c|}
\hline & $\%$ DP cells & Index \\
\hline \multicolumn{3}{|l|}{ Group } \\
\hline \multicolumn{3}{|l|}{ C57Bl/6J } \\
\hline Control + vehicle & $81 \cdot 5 \pm 1 \cdot 3$ & $100 \cdot 0 \pm 2 \cdot 5$ \\
\hline Control+RU & $82 \cdot 2 \pm 0.9$ & $100 \cdot 8 \pm 1 \cdot 3$ \\
\hline T. cruzi+ vehicle & $36 \cdot 0 \pm 2 \cdot 1^{*}$ & $44 \cdot 3 \pm 3 \cdot 1^{*}$ \\
\hline $\begin{array}{l}\text { T. cruzi+RU } \\
\text { Balb/c }\end{array}$ & $62 \cdot 0 \pm 3 \cdot 4^{*}+$ & $76 \cdot 1 \pm 4 \cdot 5^{*}+$ \\
\hline Control + vehicle & $75 \cdot 0 \pm 1 \cdot 6$ & $100 \cdot 0 \pm 1 \cdot 9$ \\
\hline Control+RU & $73 \cdot 4 \pm 0 \cdot 8$ & $97 \cdot 8 \pm 1 \cdot 2$ \\
\hline T. cruzi+vehicle & $57 \cdot 4 \pm 1 \cdot 4^{*}$ & $76 \cdot 2 \pm 1 \cdot 9 *$ \\
\hline T. cruzi+RU & $67 \cdot 0 \pm 2 \cdot 7^{*}+$ & $91 \cdot 5 \pm 3 \cdot 2 *+$ \\
\hline
\end{tabular}

The percentage of $\mathrm{CD} 4{ }^{+} \mathrm{CD} 8{ }^{+} \mathrm{DP}$ cells was determined in the thymus of non-infected (control) or infected (T. cruzi) treated with RU486 (RU) or vehicle as described in Material and Methods. Results are expressed as means \pm S.E.M. from 4 to 6 mice/group (a representative experiment from two independent series). The index was calculated as the percentage of DP cells taking as $100 \%$, the percentage of DP cells in the control mice of each strain. ${ }^{*} P<0.01$ vs control mice of the corresponding strain; $+P<0 \cdot 01$ vs $T$. cruziinfected mice of the corresponding strain (Kruskall-Wallis test).

Furthermore, when the infected Balb/c mice were treated with RU486 from day 2, the difference between the survival time of infected $\mathrm{Balb} / \mathrm{c}$ and $\mathrm{C} 57 \mathrm{Bl} / 6$ mice observed, when the treatment started on day 10 , disappeared. These results strongly indicate that the early increase in corticosterone blood levels induced by T. cruzi inoculation into Balb/c hosts contributes to protect these animals.

We have also explored whether adrenalectomy exerts effects similar to those of the blocker RU486 in T. cruziinfected $\mathrm{C} 57 \mathrm{Bl} / 6$ mice. Ablation of the adrenal glands accelerated the lethal course of the disease, comparable to treatment with the glucocorticoid receptor blocker. The survival times of infected animals were: sham-operated mice, $23 \cdot 4 \pm 1 \cdot 4$ days; adrenalectomized mice, $16 \pm 0 \cdot 8$ days $(P<0 \cdot 01$ vs sham); RU486-treated mice, $17 \cdot 0 \pm 0-6$ days

Table 4 Blockade of glucocorticoid receptors does not affect parasitemia and myocardial lesions

\begin{tabular}{|c|c|c|c|}
\hline & Parameter & Vehicle & RU486 \\
\hline \multicolumn{4}{|l|}{ Strain } \\
\hline \multirow[t]{3}{*}{ C57Bl/6J } & Parasitemia $^{a}$ & $42(4-81)$ & $45(1-75)$ \\
\hline & Amastigote nests ${ }^{\mathrm{b}}$ & $4 \cdot 7 \pm 3 \cdot 9$ & $3 \cdot 0 \pm 1 \cdot 0$ \\
\hline & Inflammatory foci ${ }^{b}$ & $11 \cdot 0 \pm 4 \cdot 2$ & $11 \cdot 2 \pm 2 \cdot 4$ \\
\hline \multirow[t]{3}{*}{ Balb/c } & Parasitemia $^{a}$ & $35(19-90)$ & $41(9-112)$ \\
\hline & Amastigote nests $^{\mathrm{b}}$ & $8 \cdot 0 \pm 1 \cdot 5$ & $6 \cdot 5 \pm 1 \cdot 0$ \\
\hline & Inflammatory foci ${ }^{b}$ & $15 \cdot 6 \pm 2 \cdot 5$ & $14 \cdot 5 \pm 2 \cdot 0$ \\
\hline
\end{tabular}

Mice were infected with T. cruzi and received RU486 or the corresponding vehicle as described in Material and Methods.

${ }^{a}$ Data represent median (rank) of parasites/50 fields from 6 to 10 mice/group (a representative experiment from two independent series) from a blood sample obtained from the tip of the tail 14 days after infection.

${ }^{\mathrm{b}}$ Total number of amastigote nests and of inflammatory foci detected in three histological sections of the heart 17 days after infection. Results are given as means \pm s.E.M. from 4 to 5 mice/group (a representative experiment from two independent series). No statistically significant differences were detected between vehicle- and RU-injected groups (Kruskall-Wallis test).

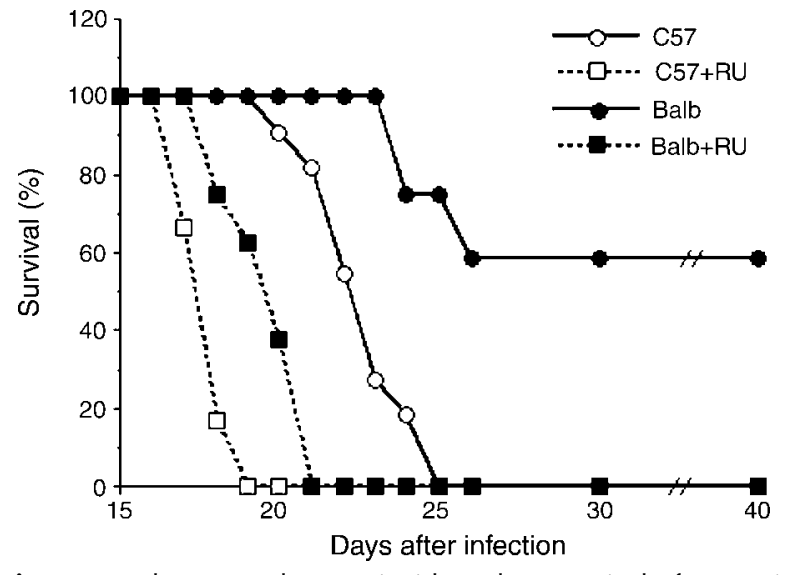

Figure 2 Endogenous glucocorticoids prolong survival of T. cruziinfected mice. Mice infected with $T$. cruzi received RU486 from day 10 after infection or the vehicle alone and the survival time was recorded. C57BI/6: infected $n=11$, infected $+R U 486 n=6$; Balb/c: infected $n=12$, infected + RU486 $n=8$.

$(P<0 \cdot 01$ vs sham $) \quad(n=7-8 /$ group $)$. No significant differences in the survival time of adrenalectomized and RU-treated mice were detected.

Blockade of glucocorticoid receptors results in increased TNF- $\alpha$ levels in blood of infected mice

It is known that TNF- $\alpha$ levels are increased during the immune response to T. cruzi (Revelli et al. 1999, Truyens et al. 1999, Holscher et al. 2000, Roggero et al. 2002) and it is likely that this cytokine is also involved in the immunopathological processes during the disease (Truyens et al. 1995, Holscher et al. 2000). On the other hand, TNF- $\alpha$ and IL-6 can also activate the HPA-axis (Bernardini et al. 1990, Besedovsky et al. 1991). Since glucocorticoids are known to block the production of several cytokines (for review, see Besedovsky \& del Rey, 1996), it was important to evaluate the concentration of these cytokines in the blood of infected mice that received

Table 5 Mortality and survival time of T. cruzi-infected mice treated with RU486 for different times

\begin{tabular}{|c|c|c|c|c|}
\hline & Parameter & Vehicle & RU D2 & RU D10 \\
\hline \multicolumn{5}{|l|}{ Strain } \\
\hline C57Bl/6J & Mortality & $11 / 11$ & 9/9 & $6 / 6$ \\
\hline & Survival time $\mathrm{e}^{\mathrm{b}}$ & $21 \cdot 8 \pm 0 \cdot 5$ & $16 \cdot 0 \pm 0 \cdot 5^{*}$ & $16 \cdot 8 \pm 0 \cdot 3 *$ \\
\hline$B a l b / c$ & $\begin{array}{l}\text { Mortality }^{\mathrm{a}} \\
\text { Survival time }\end{array}$ & $\begin{array}{l}5 / 12+ \\
23 \cdot 7+0 \cdot 4^{c}\end{array}$ & $\begin{array}{l}6 / 6 \\
15 \cdot 3+0 \cdot 3^{*} \neq\end{array}$ & $\begin{array}{l}8 / 8 \\
19 \cdot 0+0 \cdot 3 * \S\end{array}$ \\
\hline
\end{tabular}

Mice were infected with T. cruzi and received a daily i.p. injection of RU486 $(1 \mathrm{mg} / 0 \cdot 1 \mathrm{ml}$ in sesame oil) from day 2 (RU D2) or day 10 (RU D10) after infection, or the vehicle alone.

${ }^{\mathrm{a}}$ Dead mice/total mice.

${ }^{b}$ Results are given as means \pm S.E.M., in days.

cNote that the survival time is the means \pm s.E.M. of the five mice that died, since the rest (7) of the animals included in this group recovered. ${ }^{*} P<0.01$ vs vehicle of the corresponding strain. $+P<0.025$ vs RUD2 and $P<0.015$ vs RUD10. $¥ P<0.01$ vs Balb/c RUD10. $§ P<0.01$ vs C57Bl/6) RU10 (KruskallWallis test). 
$\mathrm{C} 57 \mathrm{BI} / 6$
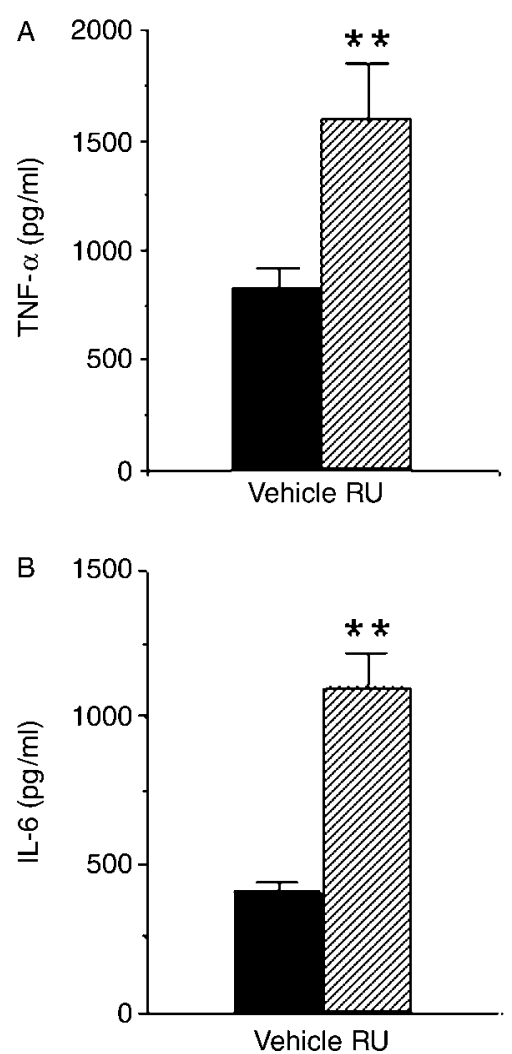

Balb/c
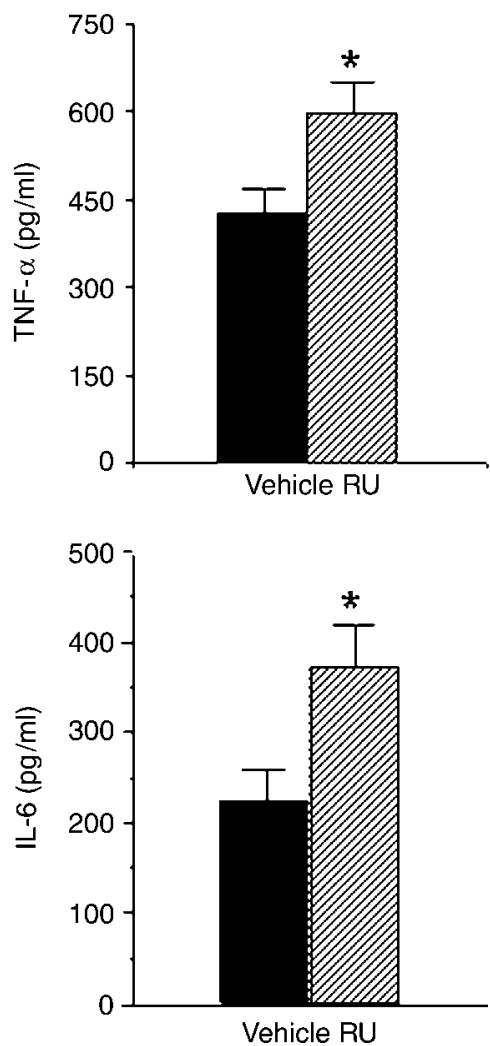

Figure 3 Blockade of glucocorticoid receptors results in increased TNF- $\alpha$ and IL- 6 levels in blood of infected mice. Mice infected with T. cruzi received RU486 from day 10 after infection or the vehicle alone. TNF- $\alpha$ (A) and IL- 6 (B) levels in plasma were determined 18 days after infection. Each column represents the means \pm s.E.M. of determinations performed in 5-8 mice. ${ }^{*} P<0 \cdot 05$ and ${ }^{* *} P<0 \cdot 01$ vs vehicle of the corresponding strain (Mann-Whitney $U$-test).

RU486. Results depicted in Fig. 3 show that the blockade of glucocorticoid receptors resulted in a significant increase in TNF- $\alpha$ and IL- 6 concentrations in the blood of C57Bl/ 6 and $\mathrm{Balb} / \mathrm{c}$ mice, although the increase was less pronounced in $\mathrm{Balb} / \mathrm{c}$ mice. However, it has to be emphasized that all mice were sacrificed 18 days after injection of the parasites, at a stage of a disease that was closer to death in RU486-treated $\mathrm{C} 57 \mathrm{Bl} / 6$ mice than in $\mathrm{Balb} / \mathrm{c}$ mice subjected to the same treatment (see Fig. 2).

\section{Discussion}

Increased glucocorticoid release, as a consequence of the stimulation of the HPA axis during the immune response, is a mechanism that protects the host from the harmful effects of pro-inflammatory cytokines and other factors, such as eicosanoids, histamine, and NO (Bertini et al. 1988, Radomski et al. 1990, Williams \& Yarwood, 1990; for review, see Besedovsky \& del Rey, 1996). Glucocorticoids can also modulate the immune response at other levels, since they can affect antigen presentation, immune cell proliferation, and induce a Th1/Th2 shift, thus suppressing cell-mediated immunity (for review, see Turnbull \& Rivier, 1999, Fleshner et al. 2001). In the model of Chagas' disease used here, the HPA axis was also stimulated following infection with T. cruzi. It is important to note that endogenous levels of corticosterone that may be immunosuppressive were markedly increased in infected mice only towards the end of the acute disease. In this context, it is relevant to mention that glucocorticoids are not always immunosuppressive. A moderate increase in endogenous corticosterone blood levels may favor immunospecificity by interfering with non-committed immune cells (for review, see Besedovsky \& del Rey, 1996), contribute to a more efficient early stage of cellular immune responses (Wiegers et al. 2001), and promote antibody production (Fleshner et al. 2001). The higher basal levels of corticosterone and the early increase in the levels of this hormone in infected $\mathrm{Balb} / \mathrm{c}$ mice, when compared to infected $\mathrm{C} 57 \mathrm{Bl} / 6$ mice, may explain why a large proportion of Balb/c mice survived the T. cruzi infection. This may reflect genetic differences between both strains, since the animals were kept in the same animal facilities and were subjected to similar experimental conditions. In support of this possibility, Balb/c mice, compared to $\mathrm{C} 57 \mathrm{Bl} / 6 \mathrm{~J}$ mice, have been reported to respond to certain types 
of stress (Lu et al. 1998) and virus (Price et al. 1996) with stronger stimulation of the HPA axis.

We and others (Leite de Moraes et al. 1991, Roggero et al. 2002, Mantuano-Barradas et al. 2003) have shown that during the acute phase of T. cruzi infection, there is a marked thymus atrophy, mainly characterized by the loss of $\mathrm{CD} 4{ }^{+} \mathrm{CD} 8^{+}$ cells. The results reported here show that endogenous glucocorticoids play an important role in mediating this effect, since blockade of the receptors for these hormones significantly reverted the reduction of DP cells observed in the infected mice. It has been shown that RU486 exerts a weak agonist effect upon binding to glucocorticoid receptors, since a limited fraction of the receptor-antagonist complex can be translocated to the nucleus and mediate the biological effects of glucocorticoids (Gruol \& Altschmied, 1993, Nordeen et al. 1993). This partial agonist effect would explain our observation of a reduced thymus weight in uninfected mice treated with RU486. The blockade of GC receptors in infected mice, which have elevated levels of corticosterone, results in a further increase in the levels of this hormone. One possibility is that prolonged treatment with RU486 interferes with the glucocorticoid feedback when the HPA axis is being stimulated by $T$. cruzi infection. This effect might not be observed under basal conditions. However, further studies are necessary to clarify this issue.

It has been reported that both $\mathrm{TNF}-\alpha$ and glucocorticoids are involved in LPS-induced thymocyte apoptosis (Kato et al. 1995). Our results would agree with this study since glucocorticoid blockade did not completely revert the reduction in thymus weight induced by the infection and, at the same time, increased TNF- $\alpha$ levels. Thus, the absence of glucocorticoid effects seems to be compensated by increased TNF- $\alpha$ levels, which have been shown to induce apoptosis in the thymus (Hernandez-Caselles \& Stutman, 1993). Our results are at variance with studies in adrenalectomized mice, in which glucocorticoids appeared not to be involved in thymus atrophy during acute T. cruzi infection (Leite de Moraes et al. 1991). Variations in the experimental conditions and study design, such as differences in parasite load and the use of a different T. cruzi strain, may account for this difference. Moreover, it should be emphasized that the existence of extra-adrenal corticosteroidogenic systems, which might be activated following adrenalectomy, has been shown (Davies \& MacKenzie, 2003). Indeed, in the study by Leite de Moraes et al. (1991), it was reported that corticosterone levels in $T$. cruzi-infected adrenalectomized animals were higher than those of non-infected counterparts.

There is evidence that the increase in endogenous glucocorticoid levels plays a protective role for the host, for example, during experimentally induced autoimmune encephalomyelitis (MacPhee et al. 1989) and arthritis (Tonelli et al. 2001). In addition, the demonstration that adrenalectomy in mice infected with lymphocyte choriomeningitis virus increases lethality as well as TNF- $\alpha$, IL-6, and IL-1 $\beta$ production (Ruzek et al. 1999) reinforces the view that glucocorticoids prevent an excessive inflammatory response. In addition, treatment of mice with RU486 enhances the susceptibility to experimental endotoxemia and the inflammatory and toxic effects of TNF- $\alpha$ (Laue et al. 1988, Lazar et al. 1992, Fan et al. 1994). The results reported here show for the first time that interference with the increase of endogenous corticosterone levels, in a model of intracellular parasite, not only accelerates death of C57Bl/6 mice, but also results in 100\% mortality in the less susceptible strain Balb/c.

The existence of a feedback circuit based on cytokineHPA axis interactions is now well established (Besedovsky \& del Rey, 1996, Turnbull \& Rivier, 1999). The data reported here showing that the blockade of glucocorticoid action resulted in a further increase in TNF- $\alpha$ production following T. cruzi inoculation show that this circuit also operates during parasite infection. Glucocorticoids inhibit the synthesis of TNF- $\alpha$ and other cytokines by interfering with the activation of transcription factors such as nuclear

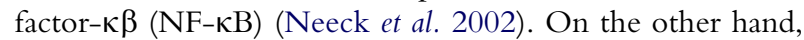
pro-inflammatory cytokines not only induce HPA activation but may also affect glucocorticoid effects by preventing the binding of these hormones to their receptors (Almawi et al. 1991, Kam et al. 1993) or by inducing the synthesis of transcription factors (as $\mathrm{NF}-\kappa \mathrm{B}$ and activator protein-1 (AP-1)) that interfere with glucocorticoid activities (Funder, 1992). Since, as mentioned, the activation of the HPA axis was observed in $\mathrm{C} 57 \mathrm{Bl} / 6$ mice during the third week of infection, it might have been ineffective to completely counteract harmful effects of TNF- $\alpha$ and other proinflammatory cytokines. In contrast, the modest, but early and prolonged, glucocorticoid increase observed in infected $\mathrm{Balb} / \mathrm{c}$ mice might have contributed to a better control of TNF- $\alpha$ production and, as consequence, to the reduced mortality rate of these animals during T. cruzi infection (Roggero et al. 2002). The role of TNF- $\alpha$ and probably of other pro-inflammatory cytokines in mediating the lethal course of the disease is supported by our observation that the blockade of endogenous glucocorticoids, when the infection was already established, did not significantly affect several pathophysiological parameters such as parasitemia and the degree of myocardial lesions, as reflected by the number of amastigote nests and inflammatory loci. In contrast, TNF- $\alpha$ production was markedly increased following administration of RU486 to T. cruzi-infected mice of both strains, indicating that this cytokine significantly contributes to lethality.

In summary, the results reported here indicate that a cytokine-HPA axis feedback circuit operates during acute infection with T. cruzi parasites. Although the activation of this circuit induced thymus involution and decreased the number of DP thymocytes, it was protective for the host, since interference with the effect of elevated glucocorticoid levels resulted in increased TNF- $\alpha$ production, accelerated death of $\mathrm{C} 57 \mathrm{Bl} / 6$ mice, and caused $100 \%$ lethality in otherwise less susceptible Balb/c mice. Thus, the present results show that not only the immune response but also an 
endocrine host response determines the course of a parasitic infection.

\section{Acknowledgements}

We thank Peter J Hanley for careful review of the manuscript. This work was supported by the Fond for Scientific and Technological Research, National Agency of Scientific and Technological Promotion, Argentina (FONCYT; grant BID 1201/OC-AR 05-06412 and 05-08555) and the Deutsche Forschungsgemeinschaft (DFG). The authors declare that there is no conflict of interest that could prejudice the impartiality of this scientific work.

\section{References}

Almawi WY, Lipman ML, Stevens AC, Zanker B, Hadro ET \& Strom TB 1991 Abrogation of glucocorticoid-mediated inhibition of $\mathrm{T}$ cell proliferation by the synergistic action of IL-1, IL-6, and IFN-gamma. Journal of Immunology 146 3523-3527.

Andrade V, Barral-Netto M \& Andrade SG 1985 Patterns of resistance of inbred mice to Trypanosoma cruzi are determined by parasite strain. Brazilian Journal of Medical and Biological Research 18 499-506.

Appelberg R, Castro AG, Pedrosa J, Silva RA, Orme IM \& Minoprio P 1994 Role of gamma interferon and tumor necrosis factor alpha during T-cellindependent and -dependent phases of Mycobacterium avium infection. Infection and Immunity 62 3962-3971.

Bernardini R, Kamilaris TC, Calogero AE, Johnson EO, Gomez MT, Gold PW \& Chrousos GP 1990 Interactions between tumor necrosis factoralpha, hypothalamic corticotropin-releasing hormone, and adrenocorticotropin secretion in the rat. Endocrinology 126 2876-2881.

Bertini R, Bianchi M \& Ghezzi P 1988 Adrenalectomy sensitizes mice to the lethal effects of interleukin 1 and tumor necrosis factor. Journal of Experimental Medicine 167 1708-1712.

Besedovsky HO \& del Rey A 1996 Immune-neuro-endocrine interactions: facts and hypotheses. Endocrine Reviews 17 64-102.

Besedovsky HO, del Rey A, Klusman I, Furukawa H, Monge Arditi G \& Kabiersch A 1991 Cytokines as modulators of the hypothalamus-pituitaryadrenal axis. Journal of Steroid Biochemistry and Molecular Biology 40 613-618.

Davies E \& MacKenzie SM 2003 Extra-adrenal production of corticosteroids. Clinical and Experimental Pharmacology and Physiology 30 437-445.

Fan J, Gong XQ, Wu J, Zhang YF \& Xu RB 1994 Effect of glucocorticoid receptor (GR) blockade on endotoxemia in rats. Circulatory Shock 42 76-82.

Fleshner M, Deak T, Nguyen KT, Watkins LR \& Maier SF 2001 Endogenous glucocorticoids play a positive regulatory role in the antikeyhole limpet hemocyanin in vivo antibody response. Journal of Immunology 166 3813-3819.

Funder JW 1992 Glucocorticoid receptors. Journal of Steroid Biochemistry and Molecular Biology 43 389-394.

Gao W \& Pereira MA 2002 Interleukin-6 is required for parasite specific response and host resistance to Trypanosoma cruzi. International Journal of Parasitology 32 167-170.

Gruol DJ \& Altschmied J 1993 Synergistic induction of apoptosis with glucocorticoids and $3^{\prime}, 5^{\prime}$-cyclic adenosine monophosphate reveals agonist activity by RU 486. Molecular Endocrinology 7 104-113.

Heinzel FP, Rerko RM \& Hujer AM 1998 Underproduction of interleukin12 in susceptible mice during progressive leishmaniasis is due to decreased CD40 activity. Cellular Immunology 184 129-142.

Hernandez-Caselles T \& Stutman O 1993 Immune functions of tumor necrosis factor. I. Tumor necrosis factor induces apoptosis of mouse thymocytes and can also stimulate or inhibit IL-6-induced proliferation depending on the concentration of mitogenic costimulation. Journal of Immunology 151 3999-4012.
Holscher C, Mohrs M, Dai WJ, Kohler G, Ryffel B, Schaub GA, Mossmann $\mathrm{H} \&$ Brombacher F 2000 Tumor necrosis factor alpha-mediated toxic shock in Trypanosoma cruzi-infected interleukin 10-deficient mice. Infection and Immunity 68 4075-4083.

Jondal M, Okret S \& McConkey D 1993 Killing of immature CD4 + CD8 + thymocytes in vivo by anti-CD3 or $5^{\prime}$-(N-ethyl)-carboxamide adenosine is blocked by glucocorticoid receptor antagonist RU-486. European Journal of Immunology 23 1246-1250.

Kam JC, Szefler SJ, Surs W, Sher ER \& Leung DY 1993 Combination IL-2 and IL-4 reduces glucocorticoid receptor-binding affinity and T cell response to glucocorticoids. Journal of Immunology 1513460 3466.

Kato Y, Morikawa A, Sugiyama T, Koide N, Jiang GZ, Takahashi K \& Yokochi T 1995 Role of tumor necrosis factor-alpha and glucocorticoid on lipopolysaccharide (LPS)-induced apoptosis of thymocytes. FEMS Immunology and Medical Microbiology 12 195-204.

Laue L, Kawai S, Brandon DD, Brightwell D, Barnes K, Knazek RA, Loriaux DL \& Chrousos GP 1988 Receptor-mediated effects of glucocorticoids on inflammation: enhancement of the inflammatory response with a glucocorticoid antagonist. Journal of Steroid Biochemistry 29 591-598.

Lazar G, Jr., Duda E \& Lazar G 1992 Effect of RU 38486 on TNF production and toxicity. FEBS Letters 308 137-140.

Leite de Moraes MC, Hontebeyrie-Joskowicz M, Leboulenger F, Savino W, Dardenne M \& Lepault F 1991 Studies on the thymus in Chagas' disease. II. Thymocyte subset fluctuations in Trypanosoma cruzi-infected mice: relationship to stress. Scandinavian Journal of Immunology 33 267-275.

Lu ZW, Song C, Ravindran AV, Merali Z \& Anisman H 1998 Influence of a psychogenic and a neurogenic stressor on several indices of immune functioning in different strains of mice. Brain, Behavior and Immunity 12 7-22.

MacPhee IA, Antoni FA \& Mason DW 1989 Spontaneous recovery of rats from experimental allergic encephalomyelitis is dependent on regulation of the immune system by endogenous adrenal corticosteroids. Journal of Experimental Medicine 169 431-445.

Mantuano-Barradas M, Henriques-Pons A, Araujo-Jorge TC, Di Virgilio F, Coutinho-Silva R \& Persechini PM 2003 Extracellular ATP induces cell death in $\mathrm{CD} 4+/ \mathrm{CD} 8+$ double-positive thymocytes in mice infected with Trypanosoma cruzi. Microbes and Infection 5 1363-1371.

Neeck G, Renkawitz R \& Eggert M 2002 Molecular aspects of glucocorticoid hormone action in rheumatoid arthritis. Cytokines Cellular and Molecular Theraphy 7 61-69.

Nordeen SK, Bona BJ \& Moyer ML 1993 Latent agonist activity of the steroid antagonist, RU486, is unmasked in cells treated with activators of protein kinase A. Molecular Endocrinology 7 731-742.

Price P, Olver SD, Silich M, Nador TZ, Yerkovich S \& Wilson SG 1996 Adrenalitis and the adrenocortical response of resistant and susceptible mice to acute murine cytomegalovirus infection. European Journal of Clinical Investigation 26 811-819.

Radomski MW, Palmer RM \& Moncada S 1990 Glucocorticoids inhibit the expression of an inducible, but not the constitutive, nitric oxide synthase in vascular endothelial cells. PNAS 87 10043-10047.

Revelli S, Gomez L, Wietzerbin J, Bottasso O \& Basombrio MA 1999 Levels of tumor necrosis factor alpha, gamma interferon, and interleukins 4,6 , and 10 as determined in mice infected with virulent or attenuated strains of Trypanosoma cruzi. Parasitology Research 85 147-150.

Roggero E, Perez A, Tamae-Kakazu M, Piazzon I, Nepomnaschy I, Wietzerbin J, Serra E, Revelli S \& Bottasso O 2002 Differential susceptibility to acute Trypanosoma cruzi infection in BALB/c and C57BL/6 mice is not associated with a distinct parasite load but cytokine abnormalities. Clinical and Experimental Immunology 128 421-428.

Ruzek MC, Pearce BD, Miller AH \& Biron CA 1999 Endogenous glucocorticoids protect against cytokine-mediated lethality during viral infection. Journal of Immunology 162 3527-3533.

Sapolsky RM, Romero LM \& Munck AU 2000 How do glucocorticoids influence stress responses? Integrating permissive, suppressive, stimulatory, and preparative actions. Endocrine Reviews 21 55-89. 
Savino W, Leite-de-Moraes MC, Hontebeyrie-Joskowicz M \& Dardenne M 1989 Studies on the thymus in Chagas' disease. I. Changes in the thymic microenvironment in mice acutely infected with Trypanosoma cruzi. European Journal of Immunology 19 1727-1733.

Tonelli L, Webster JI, Rapp KL \& Sternberg E 2001 Neuroendocrine responses regulating susceptibility and resistance to autoimmune/inflammatory disease in inbred rat strains. Immunological Reviews 184 203-211.

Truyens C, Torrico F, Angelo-Barrios A, Lucas R, Heremans H, De Baetselier P \& Carlier Y 1995 The cachexia associated with Trypanosoma cruzi acute infection in mice is attenuated by anti-TNF-alpha, but not by anti-IL-6 or anti-IFN-gamma antibodies. Parasite Immunology 17 561-568.

Truyens C, Torrico F, Lucas R, De Baetselier P, Buurman WA \& Carlier Y 1999 The endogenous balance of soluble tumor necrosis factor receptors and tumor necrosis factor modulates cachexia and mortality in mice acutely infected with Trypanosoma cruzi. Infection and Immunity 67 5579-5586.
Turnbull AV \& Rivier CL 1999 Regulation of the hypothalamic-pituitaryadrenal axis by cytokines: actions and mechanisms of action. Physiological Reviews 79 1-71.

Wiegers GJ, Stec IE, Klinkert WE, Linthorst AC \& Reul JM 2001 Bidirectional effects of corticosterone on splenic T-cell activation: critical role of cell density and culture time. Neuroendocrinology 73 139-148.

Williams TJ \& Yarwood H 1990 Effect of glucocorticosteroids on microvascular permeability. American Review of Respiratory Disease 141 S39-S43.

Wrightsman R, Krassner S \& Watson J 1982 Genetic control of responses to Trypanosoma cruzi in mice: multiple genes influencing parasitemia and survival. Infection and Immunity 36 637-644.

Received in final form 29 April 2006 Accepted 2 May 2006 